Article

\title{
The Influences of Magnesium upon Calcium Phosphate Mineral Formation and Structure as Monitored by X-ray and Vibrational Spectroscopy
}

\author{
David M. Hilger ${ }^{1, * \mathbb{D}}$, Jordan G. Hamilton ${ }^{2} \mathbb{D}$ and Derek Peak ${ }^{2}$ \\ 1 Department of Earth Sciences, University of Waterloo, Waterloo, ON N2L 3G1, Canada \\ 2 Department of Soil Science, University of Saskatchewan, Saskatoon, SK S7N 5A8, Canada; \\ jordan.hamilton@usask.ca (J.G.H.); derek.peak@usask.ca (D.P.) \\ * Correspondence: david.hilger@uwaterloo.ca
}

Received: 18 December 2019; Accepted: 18 January 2020; Published: 29 January 2020

check for updates

\begin{abstract}
Calcium phosphate minerals are typically the solubility-limiting phase for phosphate in calcareous soils. Magnesium (Mg), despite being present in high concentrations in calcareous soils, has been largely neglected in the study of formation and stabilization of soil phosphate minerals due to the high solubility of pure $\mathrm{Mg}$ phosphate phases. In this study, a series of four common calcium and magnesium phosphate minerals, hydroxyapatite/bobierrite and brushite/newberyite were synthesized in the presence of widely varying $\mathrm{Mg}$ concentrations to examine the effects of $\mathrm{Mg}$ substitution upon the local bonding environment and overall structure of the precipitates. Phosphorus K-edge X-Ray absorption near edge structure (XANES) and attenuated total reflectance Fourier transform infrared (ATR-FTIR) provide insight into the local coordination environment, whereas synchrotron powder X-Ray diffraction (SP-XRD) and transmission electron microscopy (TEM) were used for structural analysis. In acidic to neutral $\mathrm{pH}, \mathrm{Mg}$-bearing brushite phases formed over a wide range of $\mathrm{Ca}: \mathrm{Mg}$ ratios. In neutral to high $\mathrm{pH}$ systems, a short-range order amorphous calcium phosphate (ACP) with a local structure analogous with hydroxyapatite precipitated for a wide range of $\mathrm{Ca}$ to $\mathrm{Mg}$ ratios. It can be inferred that the presence of $\mathrm{Mg}$ in soils leads to stabilization of metastable phases: via cation substitution in brushite and via poisoning of crystal growth propagation for hydroxyapatite.
\end{abstract}

Keywords: phosphate; XANES; XAS; EXAFS; spectroscopy; speciation; adsorption

\section{Introduction}

Phosphorous $(\mathrm{P})$ is a macronutrient for plant and microbial growth and is integral to all life and is thus tightly coupled to global food demands. However, overapplication of phosphate to soils can also lead to environmental consequences such as eutrophication and algal blooms when soil $\mathrm{P}$ forms are mobilized via leaching, erosion, and runoff. There is a need to fully understand the chemical fate of $\mathrm{P}$ minerals in the environment to not only enhance bioavailability for crops but also to minimize losses to surface waters. To be effective in P nutrient stewardship, scientists require detailed information about the chemical forms of soil P so that they can link speciation to not only plant uptake but also environmental fate.

In temperate soil ecosystems, the solubility-limiting solid-phase phosphate mineral is often predicted to be hydroxyapatite (HAP; $\left.\mathrm{Ca}_{5}\left(\mathrm{PO}_{4}\right)_{3} \mathrm{OH}\right)$. A number of analogues exist with varying degrees of crystallinity and solubility: amorphous, calcium deficient, and carbonate substituted [1]; all are strongly favored to form at neutral to basic $\mathrm{pH}$ system and a Ca:P ratio greater than 1.67:1. In more acidic systems $(\mathrm{pH}<7)$ with less $\mathrm{Ca}(1-1.5: 1 \mathrm{Ca}: \mathrm{P})$, dicalcium phosphate dihydrate, or brushite $\left(\mathrm{DCPD} ; \mathrm{CaHPO}_{4} \cdot 2 \mathrm{H}_{2} \mathrm{O}\right)$ is stable. Interestingly, brushite has been observed in fertilized calcareous 
soils [2-4] and there is established and mounting evidence, chiefly in the biomedical field, that brushite is an important HAP precursor for many different geochemical conditions [5,6].

Magnesium is a potentially significant cation for complexation and precipitation reactions with $\mathrm{P}$ that has largely been omitted from soil $\mathrm{P}$ speciation due to the observation that pure $\mathrm{Mg}$ phases are much more soluble than Ca-P minerals [4,7]. Nonetheless, magnesium phosphate minerals, such as newberyite (NBTE; $\mathrm{MgHPO}_{4} \cdot 3 \mathrm{H}_{2} \mathrm{O}$ ) and bobierrite $\left(\mathrm{BOB} ; \mathrm{Mg}_{3}\left(\mathrm{PO}_{4}\right)_{2} \cdot 8 \mathrm{H}_{2} \mathrm{O}\right)$ have been identified in systems where there is an abundance of $\mathrm{Mg}$ due to amendment applications or parent material [4,8-10]. In biomaterial studies, and more recently in soil chemistry, $\mathrm{Mg}$ has been shown to strongly inhibit the formation of crystalline minerals such as hydroxyapatite [4,11-15], whereas more soluble phases like brushite are minimally affected by $\mathrm{Mg}[11,12]$. Specifically, it has been observed in basic solutions that HAP precipitation is inhibited by $10 \%$ or higher $\mathrm{Mg}$ substitution for $\mathrm{Ca}$, and amorphous calcium phosphate (ACP) or whitlockite, the Mg polymorph of $\beta$-tri-calcium phosphate, forms instead $[4,15-17]$. As both of these Mg-bearing products are nanoparticles, it has been difficult to differentiate these phases from a truly amorphous material with many spectroscopic techniques or chemical fractionation [3].

It is somewhat surprising that missing components in the fate of soil phosphate persist, given its importance to the fate of phosphate in terrestrial ecosystems. One explanation for this knowledge gap is that direct P speciation in soils is analytically challenging. In soil systems, Nuclear Magnetic Resonance, X-Ray Diffraction, and infrared techniques all have significant issues due to the need for sample extraction to overcome matrix effects and also due to low concentration of $\mathrm{P}$ within soils [18]. Phosphorus K-edge X-ray absorption near edge spectroscopy (XANES) is an established technique [19-22] for direct solid-state P speciation in soils that has matured as the accessibility of suitable synchrotron radiation sources and beamlines has increased [23-26]. However, the utility of P XANES spectroscopy is limited in many cases by the breadth and quality of spectral reference libraries that are used in semi-quantitative analysis. Spectral libraries are available, notably that of Ingall et al., (2011), [27] but most studies have utilized highly crystalline minerals and focused towards acidic, weathered systems where $\mathrm{Fe}$ and $\mathrm{Al}$ phosphates dominate. A review of XANES features of calcium phosphates has been recently attempted to determine (a) optimized data reduction approaches and (b) diagnostic peak height ratios for a range of calcium phosphate minerals [28], but this approach relied upon compilation of data collected by many researchers rather than a systematic synthesis approach followed by uniform sample dilutions. Furthermore, such studies are not able to readily determine whether phosphate mineralogy may shift in mixed Ca:Mg conditions that are more typical of calcareous soils. Accordingly, this study focused on systematically varying $\mathrm{Mg}$ substitution into two common calcium phosphate minerals that are common in acidic and neutral conditions; i.e., brushite and hydroxyapatite.

The objective of this study was to determine the controls upon $\mathrm{Mg}$ substitution into brushite and $\mathrm{HAP}$, and then produce XANES spectra of mixed Ca-Mg phases to develop a more complete XANES spectral library for earth science researchers. We hypothesize that inclusion of $\mathrm{Mg}$ can result in changes in the XANES spectra of phosphate minerals that are more representative of soil systems and as a result may lead to more accurate phosphate speciation and thus not only improved agricultural fertilizer use efficiencies but also environmental protection.

\section{Materials and Methods}

\subsection{Mineral Synthesis}

A summary of the conditions used to produce pure and Mg-substituted phosphate minerals is tabulated in Table 1. More details of synthesis for brushite, newberyite, hydroxyapatite, and bobierrite minerals are detailed below. 
Table 1. Elemental composition of synthesized minerals exhibiting proportions of $\mathrm{Mg} / \mathrm{Ca}$ substitution.

\begin{tabular}{cccccc}
\hline & \multicolumn{5}{c}{ Final Solid Composition (Ca:Mg) } \\
\hline & \multicolumn{2}{c}{ Acidic } & \multicolumn{2}{c}{ Basic } \\
\hline $\begin{array}{c}\text { Initial Solution } \\
\text { (Ca:Mg) }\end{array}$ & $\begin{array}{c}\text { \% Initial } \\
\text { Ca }\end{array}$ & DCPD ${ }^{+}$ & NBTE $\ddagger$ & HAP $\$$ & BOB ${ }^{\text {II }}$ \\
\hline $1: 0$ & 100 & $1: 0$ & - & $1: 0$ & - \\
$20: 1$ & 95 & - & - & $1: 0.02$ & - \\
$10: 1$ & 90 & - & - & $1: 0.02$ & - \\
$5: 1$ & 80 & - & - & $1: 0.06$ & - \\
$3: 1$ & 75 & $1: 0.05$ & - & - & - \\
$1: 1$ & 50 & $1: 0.35$ & - & - & - \\
$1: 3$ & 25 & - & $0.7: 1$ & - & $0.59: 1$ \\
$1: 8$ & 12.5 & - & $0.35: 1$ & - & $0.21: 1$ \\
$0: 1$ & 0 & - & $0: 1$ & - & $0: 1$ \\
\hline
\end{tabular}

${ }^{+} \mathrm{DCPD}=$ brushite; ${ }^{\ddagger} \mathrm{NBTE}=$ newberyite; ${ }^{\S} \mathrm{HAP}=$ hydroxyapatite; ${ }^{\text {II }} \mathrm{BOB}=$ bobierrite.

\subsubsection{Brushite $\left(\mathrm{CaHPO}_{4} \cdot 2 \mathrm{H}_{2} \mathrm{O}\right)$ and Related Mixed Species Synthesis}

Pure brushite was synthesized by the dropwise mixing of equimolar $\mathrm{CaCl}_{2}$ and $\mathrm{Na}_{2} \mathrm{HPO}_{4}$ [29]. Briefly, $50 \mathrm{mmol} \mathrm{CaCl}$ were slowly dripped into $50 \mathrm{mmol} \mathrm{Na}_{2} \mathrm{HPO}_{4}$ while stirring at $25{ }^{\circ} \mathrm{C}$ with unregulated $\mathrm{pH}$. A series of $\mathrm{Mg}$-bearing brushite was created using the same method but using $\mathrm{MgCl}_{2} \cdot 6 \mathrm{H}_{2} \mathrm{O}$ in the proportions of 100:0, 75:25, 68.75:31.25, 62.50:37.50, 56.25:43.75, 50:50, 25:75, and 0:100 (Ca:Mg molar ratio). Samples were vacuum filtered with $40 \mu \mathrm{m}$ filter paper, washed with double deionized (DDI) $\mathrm{H}_{2} \mathrm{O}$, and dried at $80{ }^{\circ} \mathrm{C}$ overnight. The precipitate was referenced in all measurements by a commercially acquired equivalent (calcium phosphate dibasic dihydrate, Sigma Aldrich (Oakville, ON, Canada).

\subsubsection{Newberyite $\left(\mathrm{MgHPO}_{4} \cdot 3 \mathrm{H}_{2} \mathrm{O}\right)$ and Related Mixed Species Synthesis}

Newberyite was synthesized by the dropwise mixing of $\mathrm{MgCl}_{2} \cdot 6 \mathrm{H}_{2} \mathrm{O}$ and $\mathrm{H}_{3} \mathrm{PO}_{4}$ with a slight modification of the method of Aramendia et al., (1999) [30]. Phosphoric acid was neutralized to $\mathrm{pH}$ 7.0 with concentrated $\mathrm{NaOH}$ before the reaction to prevent over acidification. Reaction conditions were $25^{\circ} \mathrm{C}$ between $\mathrm{pH} 6.0$ and 7.4 , and $0.067 \mathrm{M} \mathrm{MgCl}_{2} \cdot 6 \mathrm{H}_{2} \mathrm{O}$ and $0.1 \mathrm{M} \mathrm{H}_{3} \mathrm{PO}_{4}$. Three additional precipitation reactions with mixed $\mathrm{Ca}: \mathrm{Mg}$ solutions were performed. Calcium substitution was performed through the replacement of $\mathrm{MgCl}_{2} \cdot 6 \mathrm{H}_{2} \mathrm{O}$ with $\mathrm{CaCl}_{2}$ in molar ratios of 12.5:87.5, 25:75, and 50:50 (Ca:Mg). As per the cited source, the precipitate was separated from the supernatant by vacuum filtration with a $40 \mu \mathrm{m}$ cellulose filter then washed several times with $\mathrm{DDI} \mathrm{H}_{2} \mathrm{O}$ to remove entrained ions. The sample was then dried at $80^{\circ} \mathrm{C}$. The precipitate was referenced in all measurements by a commercially acquired equivalent (Magnesium hydrogen phosphate trihydrate, Alfa Aesar (Haverhill, MA, USA)).

\subsubsection{Hydroxyapatite $\left(\mathrm{Ca}_{5}\left(\mathrm{PO}_{4}\right)_{3}(\mathrm{OH})\right)$ and Related Mixed Species Synthesis}

Hydroxyapatite was synthesized by the methods of Riman et al., (2007) [31]. Two solutions, one of $16.7 \mathrm{mM} \mathrm{Ca}\left(\mathrm{CH}_{3} \mathrm{COO}\right)_{2} \cdot \mathrm{H}_{2} \mathrm{O}$ and the other of $10.0 \mathrm{mM}$ of $\mathrm{H}_{3} \mathrm{PO}_{4}$, are rapidly mixed then stirred and reacted for $1 \mathrm{hr}$ with $\mathrm{pH}$ adjusted to 9.0 using $1.0 \mathrm{M} \mathrm{NaOH}$. Nitrogen gas was bubbled through the system during the reaction to minimize carbonate substitution. Magnesium substitution was performed via replacing a portion of the $\mathrm{Ca}\left(\mathrm{CH}_{3} \mathrm{COO}\right)_{2} \cdot \mathrm{H}_{2} \mathrm{O}$ with $\mathrm{Mg}\left(\mathrm{CH}_{3} \mathrm{COO}\right)_{2} \cdot 4 \mathrm{H}_{2} \mathrm{O}$ in molar proportions of 100:0, 95:5, 90:10, and 80:20. This amount of substitution was chosen based upon previous studies [32,33]. Precipitates were vacuum filtered through $40 \mu \mathrm{m}$ cellulose filters, washed with DDI $\mathrm{H}_{2} \mathrm{O}$, and dried at $110^{\circ} \mathrm{C}$. The precipitate was referenced in all measurements by a commercially acquired equivalent (Calcium phosphate tribasic, Alfa Aesar). 


\subsubsection{Bobierrite $\left(\mathrm{Mg}_{3}\left(\mathrm{PO}_{4}\right)_{2} \cdot 8 \mathrm{H}_{2} \mathrm{O}\right)$ and Related Mixed Species Synthesis}

Synthesis of bobierrite minerals was based on European Patent method 0113153 (Sherif, 1987). The formation of bobierrite occurs in two stages: a rapid room temperature mixing of $5.00 \mathrm{mmol}$ of concentrated $\mathrm{H}_{3} \mathrm{PO}_{4}$ with $2.50 \mathrm{mmol}$ of $\mathrm{Mg}(\mathrm{OH})_{2}$ to form a $100 \mathrm{~mL}$ "newberyite like" suspension followd by stepwise addition of this acidic newberyite solution into a $5 \mathrm{mM} \mathrm{MgOH}_{2}$ slurry. The second reaction occurs at $50{ }^{\circ} \mathrm{C}$ over $5 \mathrm{~h}$. As our study sought to form bobierrite with increasing amounts of Ca substitution, we used calcium hydroxide $\left(\mathrm{Ca}(\mathrm{OH})_{2}\right)$ to replace $\mathrm{Mg}(\mathrm{OH})_{2}$ as a reagent in the second reaction step in proportions of 0:100, 12.5:87.5, 25:75, and 50:50 (Ca:Mg molar ratio), with the hope this would result in increasing cation substitution. Precipitates were vacuum filtered, washed with DDI $\mathrm{H}_{2} \mathrm{O}$, and oven dried at $80^{\circ} \mathrm{C}$ overnight. The precipitate was referenced in all measurements by a commercially acquired equivalent (Magnesium phosphate tribasic octahydrate-Sigma Aldrich).

\subsection{Synchrotron Powder X-Ray Diffraction}

Synchrotron Powder X-ray Diffraction (SP-XRD) patterns of the Ca and Mg minerals were collected at the Canadian Light Source (CLS) on the Canadian Macromolecular Crystallography Facility 2 beamline CMCF-BM (08B1-1). The incident energy was $18 \mathrm{keV}$ with a wavelength of 0.6888 angstroms and the detector distance set at $250 \mathrm{~mm}$. The precipitates were finely ground and packed into polyamine tubing of $0.215 \mathrm{~mm}$ diameter. Collected patterns were calibrated to $\mathrm{LaB}_{6}$ diffraction patterns, corrected via subtraction of a polyamine tubing blank, and integrated from diffraction rings to peak patterns using GSAS II [34]. HIGHSCORE (PANalytical, Almelo, Netherlands) and GSAS I were used in phase identification of the patterns $[35,36]$.

\subsection{Attenuated Total Reflectance Fourier Transform Infrared (ATR-FTIR) Spectroscopy}

All powdered samples were analyzed with ATR-FTIR spectroscopy using a Bruker Equinox 55 FTIR spectrometer with a single bounce accessory equipped with diamond-coated ZnSe optics and a liquid nitrogen cooled Mercury-Cadmium-Tellurium (MCT) detector. Desiccated samples were ground with a mortar and pestle before analysis to ensure a firm pressing on the diamond surface and measured in the mid-infrared region between 4000 and $400 \mathrm{~cm}^{-1}$ with $4 \mathrm{~cm}^{-1}$ resolution.

\subsection{Elemental Analysis}

Samples were dissolved in a solution of $37 \% \mathrm{HCl}$ and $65 \% \mathrm{HNO}_{3}$ then microwave digested via EPA method 3051. Magnesium and Ca measured with an Agilent Microwave Plasma Atomic Emission Spectrograph 4100 (MP-AES) (Agilent Technologies, Mississauga, ON, Canada).

\subsection{Transmission Electron Microscopy (TEM)}

The pure and cation substituted phases were suspended in $\mathrm{H}_{2} \mathrm{O}$ and deposited on a copper mesh grid with a pipette. Samples were imaged with a Philips CM10 (1990, Philips Electron Optics, Eindhoven, The Netherlands) TEM with an accelerating voltage of $80 \mathrm{kV}$ which has a resolution of $0.5 \mathrm{~nm}$ at a point and $0.34 \mathrm{~nm}$ on the line with a magnification of 20,000-450,000. Images were processed with Adobe Photoshop.

\subsection{Phosphorus K-Edge XANES Spectroscopy}

All P K-edge XANES spectra were collected in partial fluorescence (PFY) mode at the Canadian Light Source (CLS) at beamline 06B1-1, the Soft X-Ray Micro-characterization Beamline (SXRMB). The storage ring of the facility operates at an energy of $2.96 \mathrm{GeV}$ and a stored current between 225-150 mA. Spectra were collected using an InSb (111) monochromator $\left(\Delta \mathrm{E} / \mathrm{E}=3.3 \times 10^{-4}\right)$ and a four-element Si-drift fluorescence detector (Bruker). Samples were diluted to $1 \%$ wt. P with BN to minimize self-absorption effects associated with PFY. Powders were ground with an agate mortar and pestle to minimize particle size effects on XANES intensities, thinly spread on double-sided carbon 
tape, and mounted on a copper plate. A minimum of two spectra were collected for each mineral sample, which were then averaged. A check of beamline resolution and stability was performed after every storage ring injection by measuring a $\mathrm{BN}$ diluted $\mathrm{ZnPO}_{4}$ standard. Samples were scanned from 2120 to $2220 \mathrm{eV}$, with a step size of $0.5 \mathrm{eV}$ from $2140-2190 \mathrm{eV}$ and a larger step pre and post edge.

\section{Results}

Brushite/Newberyite mineral series: Synchrotron-based XAS and XRD (Figure 1) and laboratory-based FTIR and TEM (Figure 2) were used to examine different aspects of structural changes due to cationic substitution into the structure of the $\mathrm{MeHPO}_{4} \cdot \mathrm{H}_{2} \mathrm{O}$ mineral series. Brushite with increasing $\mathrm{Mg}$ substitution was synthesized with starting $\mathrm{pH}$ of 5.4, whereas newberyite synthesis with increasing Ca substitution occurred at pH 6.0-7.0. (Results from the newberyite series is found in Supplemental Information). In both cases, identifiable differences in the minerals formed as a function of initial solution Ca:Mg composition occurred in low $(0 \%-25 \%$ denoted by orange spectra in Figures 1 and 2), medium ( $25 \%-75 \%$ denoted by green spectra in Figures 1 and 2$)$, and high levels $(87.5 \%-100 \%$ denoted by blue spectra in Figures 1 and 2) of substituent cation present.

Brushite/Newberyite, low $\mathrm{Mg}^{2+}$ : In this study, low levels of $\mathrm{Mg}$ in solution, $<25 \%$, have little effect on the structure of the brushite formed. There is a slight discrepancy in XRD patterns as the relative peak intensities of lower d-spacings are skewed relative to published parameters and Miller indices, but all diffractograms are consistent with a pure brushite phase [37]. The local structure of these minerals, based on P K-edge XANES spectra, are also unaffected by Mg incorporation (Figure 1, left-orange). Diagnostic spectral features such as the white line intensity and energy position, post edge shoulder, and oxygen oscillations at 2162 and $2170 \mathrm{eV}$ are consistent with unsubstituted brushite. Corroborating evidence is presented in the ATR-FTIR spectra (Figure 2A). Infrared spectra of pure and $25 \% \mathrm{Mg}$-bearing brushite are consistent with standard spectra from commercially acquired minerals, primarily based on the diagnostic close triplet of peaks around $1000 \mathrm{~cm}^{-1}$. These features are located at $\left(v_{1} \mathrm{PO}\right) 983,\left(v_{3} \mathrm{PO}\right) 1043$, and $\left(v_{3} \mathrm{PO}\right) 1115 \mathrm{~cm}^{-1}$ associated with PO vibrations (Figure 2A). A shift of $5-10 \mathrm{~cm}^{-1}$ to higher wavenumber occurs in the $v_{3} \mathrm{PO}$ vibration with the addition of $25 \% \mathrm{Mg}$ in solution, $\left(v_{1} \mathrm{PO} 983 \mathrm{~cm}^{-1}, v_{3} \mathrm{PO} 1054 \mathrm{~cm}^{-1}\right.$, and $\left.v_{3} \mathrm{PO} 1120 \mathrm{~cm}^{-1}\right)$. This shift indicates there is a change in the local environment, but there is no lack of definition or peak broadening to indicate that there are multiple bonding environments or significant strain (Figure S4 in Supplemental Materials). Morphologically (Figure 2D), brushite formed in exclusively Ca solution is aggregated in rod crystals where the length is much greater than the width, on the order of $1000 \mathrm{~nm}$ in length and $100 \mathrm{~nm}$ in width. A noticeable change is identifiable with $\mathrm{Mg}$ inclusion in the formation solution. The crystallites of brushite containing low levels of $\mathrm{Mg}$ in solution are smaller, spherical or ovoid in shape, and appear to be much less uniform. These minerals are all heavily aggregated, either from sample preparation or solution conditions, which makes identification of specific particle dimensions difficult but are approximately $200 \times 150 \mathrm{~nm}$. 

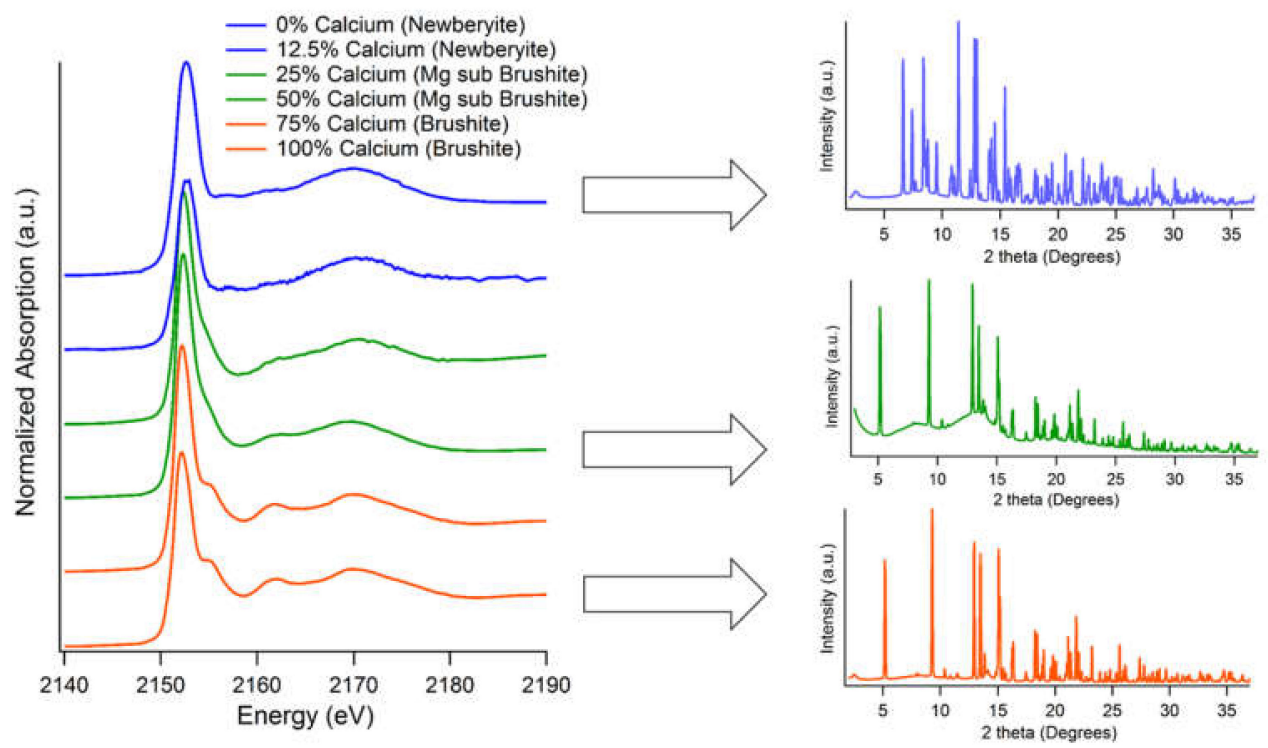

Figure 1. XANES and XRD patterns of acidic/neutral mineral series. Blue spectra/patterns indicate magnesium phosphates, green spectra indicate minerals formed in mixed cation solutions with unique characteristics, and orange spectra are crystalline calcium phosphates. Percentages refer to initial solution composition during synthesis.

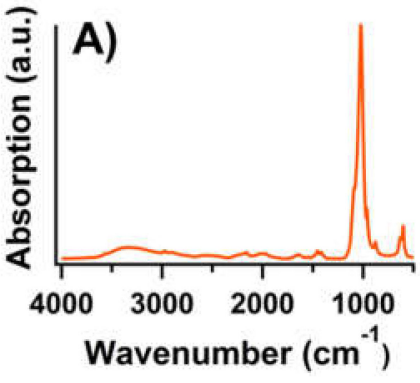

D)

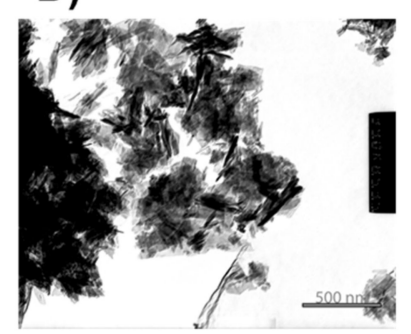

B)

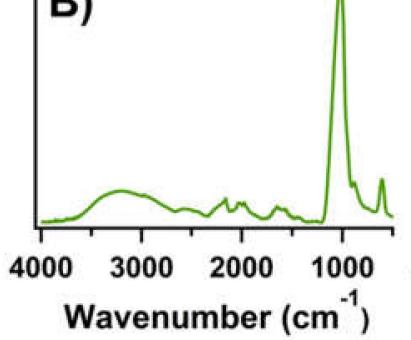

E)

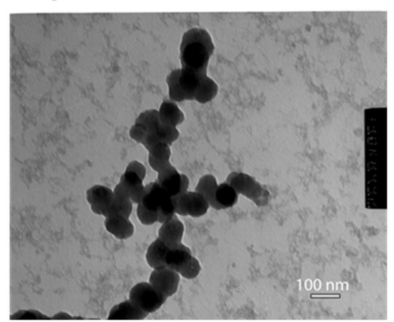

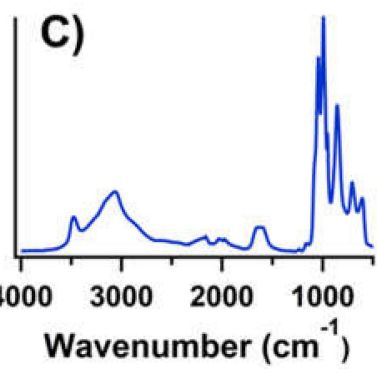

F)

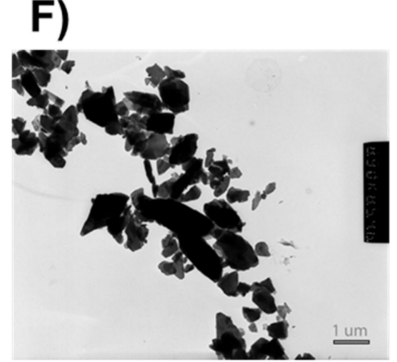

Figure 2. ATR-FTIR (top) and TEM images (bottom) of the brushite/newberyite series: (A,D) pure brushite, (B,E) Mg-brushite formed from 1:1 (Ca:Mg) solution ratio, (C,F) pure newberyite. Larger versions of ATR-FTIR spectra are available in the Supplementary information.

Brushite/Newberyite, medium $\mathrm{Mg}^{2+}$ : In solutions that are roughly equimolar in respect to Ca and $\mathrm{Mg}$, and range in $\mathrm{pH}$ from 5.4 to 7.0 , a precipitate was produced that is consistent with brushite that has a strained local structure. The overall crystal lattice is largely the same, but the local bonding environment is altered, chiefly observed via P K-edge XANES spectra that are much more altered from pure brushite than is the XRD pattern (Figure 1, green). The crystal lattice of these minerals are not different from a pure brushite phase. The chief difference is a raised background through $4^{\circ}$ to $25^{\circ}$ that is consistent with increased amorphous content and/or disorder in the structure of the mineral [38]. This is plausible, since Mg substitution into the brushite crystal lattice will result in strain due to the smaller atomic radius of Mg [11]. The ATR-FTIR and P K-edge XANES spectra are 
more sensitive to the local structure and show a more dramatic change in spectral features. The most apparent change in the XANES spectra is the loss of definition of the post edge shoulder, which decreases from a $1 \mathrm{eV}$ "ledge" to smaller feature (Figure 1); the intensity of the oscillation at $2162 \mathrm{eV}$ is also decreased. As these spectral features are diagnostic of calcium phosphates and have a positive correlation with the crystallinity of these minerals [20], it can be inferred that these phases are less crystalline than pure Ca-only phase but that are still essentially a mineral with the same structure. Similarly, the ATR-FTIR spectra are heavily modified in equimolar cation solutions. In systems with moderate concentrations of $\mathrm{Mg}$ relative to $\mathrm{Ca}$ (Figure 2B), the spectra have very broadened features: the triplet of $\mathrm{PO}$ around $1050 \mathrm{~cm}^{-1}$ is not present. Instead, there is one broad peak centered at 1049 $\mathrm{cm}^{-1}$, a $1647 \mathrm{~cm}^{-1}$ vibration due to $\mathrm{H}-\mathrm{O}-\mathrm{H}$ bending that is present but broadened, and a $\mathrm{vOH}^{-}$stretch at $3300 \mathrm{~cm}^{-1}$. This peak broadening and loss of features are also consistent with the strain that $\mathrm{Mg}$ causes on the crystal structure, resulting in a range of slightly different bond distances and symmetries all with slightly different IR stretches that appear as a broad peak. Transmission Electron Microscopy images are not largely different than those of $25 \%$ substituted brushite and show precipitates with smaller dimensions, spherical or ovoid in shape, less uniform and heavily aggregated in Figure 2E. The particle size is smaller with moderate $\mathrm{Mg}$ substitution, on the order of $120 \times 80 \mathrm{~nm}$, rather than 200-150 $\mathrm{nm}$ in low Mg substitution.

Brushite/Newberyite, high $\mathrm{Mg}^{2+}$ : At high Mg concentrations (above 1:8), the solution exclusively orms newberyite, a neutral/acidic magnesium phosphate phase. These phases have little to no Ca inclusion, with XRD consistent with newberyite patterns (Figure 1). This pattern may appear to be a mixture, but newberyite is of the low symmetry triclinic space group which produces many diffraction peaks. Phosphorus K-edges XANES spectra of these minerals are not rich with spectral features but are distinct from calcium phosphate phases. The white line intensities of magnesium phosphate phases are shifted slightly $(\sim 0.5 \mathrm{eV})$ to higher energy and have no post edge shoulder or oscillation at $2162 \mathrm{eV}$. There is a very slight peak at $2155 \mathrm{eV}$ that is more pronounced in some newberyite standard compounds than in the mixed phases produced in this study. The local bonding environment is also (>1:8 Ca:Mg) consistent with newberyite when measured using ATR-FTIR (Figure 2C). The PO stretches are present in a prominent peak located at $1016 \mathrm{~cm}^{-1}$, and lesser peaks located at $1156 \mathrm{~cm}^{-1}$ and $883 \mathrm{~cm}^{-1}$. There is also a relatively strong absorbance band at $3250 \mathrm{~cm}^{-1}$. The crystallites formed in solutions with $0 \% \mathrm{Ca}$ have a wide size distribution, but a rough average particle dimensions are $500 \times 400 \mathrm{~nm}$ based upon TEM (Figure 2F). The particles of newberyite containing $12.5 \% \mathrm{Mg}$ in solution are aggregated, roughly ovoid particles with a rough dimension of $150 \times 130 \mathrm{~nm}$.

\section{Hydroxyapatite and Bobierrite Mineral Series}

Hydroxyapatite/Bobierrite, low $\mathrm{Mg}^{2+}$ : Solutions containing a very high proportion of $\mathrm{Ca}$ to $\mathrm{Mg}$, 20:1, produce a precipitate structurally similar to pure hydroxyapatite mineral. There is a decrease in $\mathrm{Ca}$ in the mineral (Table 1) but no corresponding increase in $\mathrm{Mg}$ inclusion. The Ca:Mg ratio associated with this mineral is less than 0.02 , which may be entirely due to surface adsorption rather than incorporation. Based on this information, it can speculated that the mineral is a calcium-deficient hydroxyapatite (CDHA) [1], with local bonding environment that is not drastically different from pure hydroxyapatite. Phosphorus K-edge XANES and ATR-FTIR spectra exhibit the diagnostic features that are associated with HAP with several differing spectral characteristics (Figures 3 and 4A). The 20:1 mineral features the "wide" post-edge shoulder located at $2155 \mathrm{eV}$ in the P K-edge XANES spectra associated with crystalline Ca-P phases. In the ATR-FTIR spectra, a v3PO peak is located at $1027 \mathrm{~cm}^{-1}$ with slight peaks/shoulders for (v3PO) at $1087 \mathrm{~cm}^{-1}$ and (v1PO) $962 \mathrm{~cm}^{-1}$. It is worth noting that, in contrast with CDHA, there does not appear to be the inclusion of water in the crystal structure that is associated with amorphous calcium phosphate (ACP). Water inclusion is exhibited by defined peaks, such as those found in brushite (Figure 3) or bobierrite (Figure 4C) in the $3200-3400 \mathrm{~cm}^{-1}$ region. The broad, relatively low intensity absorbance band at $3300 \mathrm{~cm}^{-1}$ found in the $20: 1$ mineral corresponds to $\mathrm{H} 2 \mathrm{O}$, but not inclusion in the structure. Full dehydration requires high temperature, which increases 
crystallinity and forms the $\beta$-tricalcium phosphate analog whitlockite if $\mathrm{Mg}$ is present $[15,39]$. On the "macro" scale, the mineral (Figure S5 in Supplemental Materials) is considerably different than a pure phase HAP. When analyzed with TEM, the mineral was difficult to de-aggregate but is clearly not composed of the thin, platy sheets approximately $200 \times 50 \mathrm{~nm}$ that were found in pure HAP.
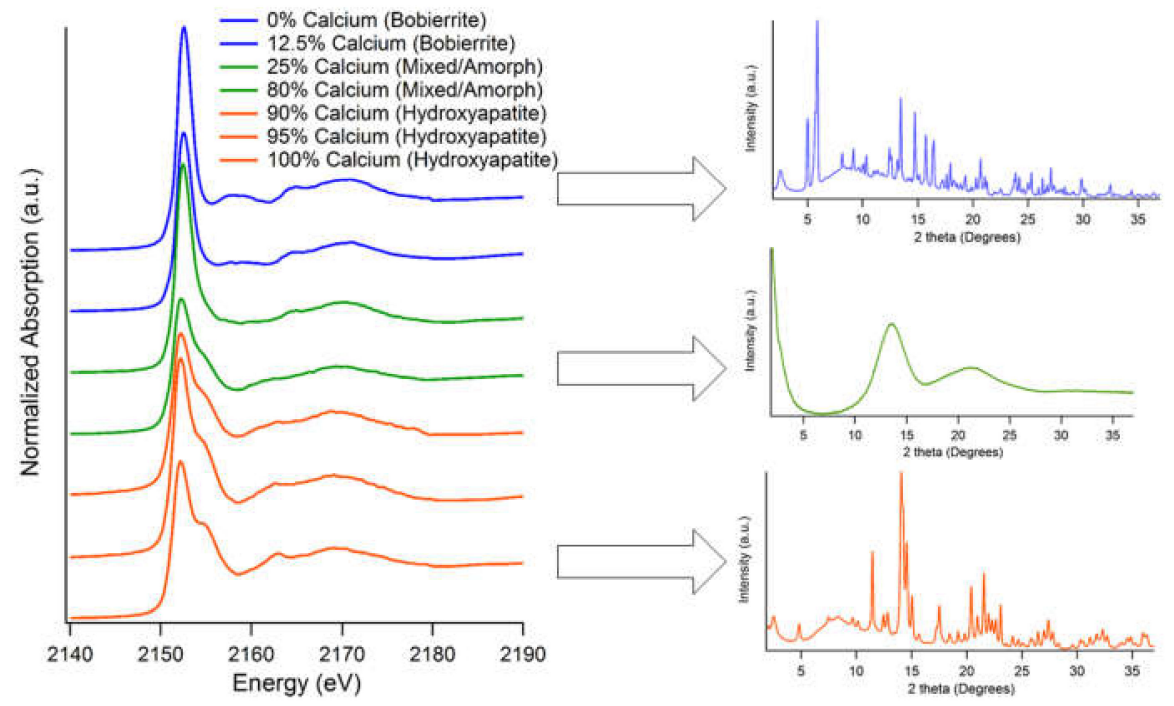

Figure 3. Hydroxyapatite/amorphous calcium phosphate/bobierrite P K-edge XANES and XRD, Blue spectra/patterns indicate magnesium phosphates, green spectra indicate minerals formed in mixed cation solutions with unique characteristics (i.e., ACP), and orange spectra are crystalline calcium phosphates. Percentages refer to initial solution conditions during synthesis.

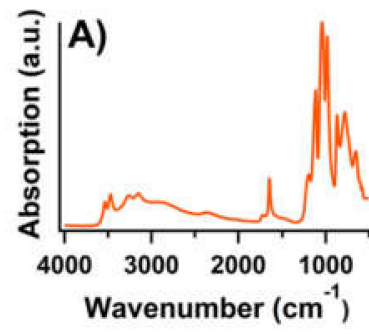

D)

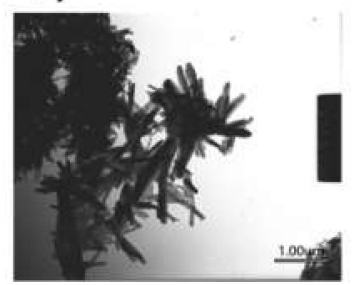

B)

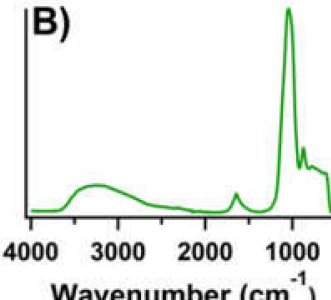

E)

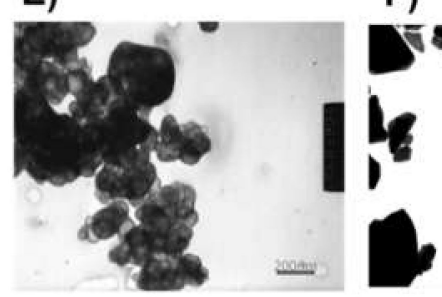

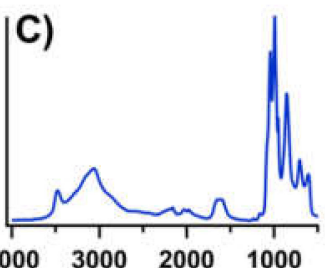

Wavenumber $\left(\mathrm{cm}^{-1}\right)$

F)

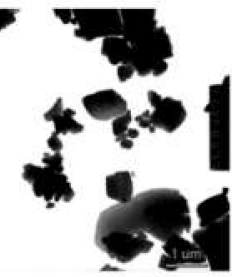

Figure 4. ATR-FTIR (top) and TEM images (bottom) of the apatite/bobbierite series: (A,D) pure hydroxyapatite, (B,E) hydroxyapatite/amorphous calcium phosphate formed from 5:1 (Ca:Mg) initial solution conditions, $(\mathbf{C}, \mathbf{F})$ pure bobierrite. Larger versions of ATR-FTIR spectra are available in the Supplementary information.

Hydroxyapatite/ bobierrite, $5 \%-75 \% \mathrm{Mg}^{2+}$ : Precipitates formed in solutions comprising of 10 to $50 \% \mathrm{Mg}$ are similar to HAP in regard to local bonding environment but are structurally distinct. (Table 1) The Ca:P ratio of these minerals falls within the range of what is considered ACP: 1.41 in the 5:1 mineral to 1.34 in 1:1 mineral [1]. There is no corresponding increase in Mg content that would indicate significant cationic substitution; the $5: 1$ ratio synthesized mineral is only $6.0 \% \mathrm{Mg}$ in the solid-state. The XRD patterns of these phases are amorphous, with no defined peaks and only 
two broad, low-intensity features located at 14 and $22^{\circ} 2 \theta$ (Figure 3). The P K-edge XANES of these "amorphous" substituted phases are consistent with slightly altered hydroxyapatite spectra, where the post edge shoulder and $2162 \mathrm{eV}$ oscillations are less defined. Similarly, the ATR-FTIR spectra are altered, with the intensity of the peak at $1027 \mathrm{~cm}^{-1}\left(v_{3} \mathrm{PO}\right.$ with carbonate) being decreased, the band at $962 \mathrm{~cm}^{-1}\left(v_{1} \mathrm{PO}\right)$ becoming more prominent, and the shoulder of $1087 \mathrm{~cm}^{-1}\left(v_{3} \mathrm{PO}\right)$ absent. The relative intensity of the $v \mathrm{OH}^{-}$stretch at $3300 \mathrm{~cm}^{-1}$ is of greater magnitude, though this is possibly due to a decrease in the intensity of the main $\mathrm{PO}_{4}$ absorbance. However, particles of these precipitates are strikingly different when examined via TEM (Figure 4D-F). The 5:1 mineral is composed of chains of spherical/ovoid individuals with a binary size distribution. The larger crystallites within this binary distribution are approximately $125 \mathrm{~nm}$ in width and while the smaller particles are $30 \mathrm{~nm}$ in dimensions.

Hydroxyapatite/bobierrite, $75 \%-100 \% \mathrm{Mg}^{2+}$ : Magnesium-rich alkaline conditions will form a mineral precipitate that is consistent with bobierrite from XRD (Figure 3). The local bonding environment of bobierrite is not affected by the mixed cation solution. Phosphorus K-edge XANES spectra feature the diagnostic features of bobierrite: white line energy and a twin set of oxygen oscillations shifted to higher energy (by $\sim 1 \mathrm{eV}$ ) relative to the XANES spectra of calcium phosphate minerals. The ATR-FTIR spectrum of concentrated $\mathrm{Mg}$ systems is unchanged from the pure bobierrite phase and distinct from systems which are predominantly Ca due to more prominent $v_{3} \mathrm{PO}$ vibrations, located at 1010, 1041, and $1066 \mathrm{~cm}^{-1}$. There is also a large spectral contribution in the 3500 to $3100 \mathrm{~cm}^{-1}$ region that are associated with the $\mathrm{vOH}^{-}$stretches of water, which is expected since the structure of this mineral contains eight different crystallographic positions for water molecules. Synthesized $0 \%$ Ca-bobierrite is composed of particles of varying size and morphology. These particles are generally composed of straight lines and angles as opposed to being curved or ovoid in nature with a wide range of crystals from $275 \times 175 \mathrm{~nm}$ to $630 \times 430 \mathrm{~nm}$. These particles are not observed in mixed cation solutions of 1:4 and 1:8; instead aggregated spherical or ovoid crystals that are under $200 \mathrm{~nm}$ in diameter and as small as $60 \mathrm{~nm}$ are found.

\section{Discussion}

For brushite/newberite, there is a threshold Ca:Mg ratio of approximately 3:1; if $\mathrm{Mg}$ is less than this value, brushite forms without its crystal structure being substantially altered. Magnesium does have some impact on mineral formation in this substitution range, as the crystallite macrostructure of low $\mathrm{Mg}$ brushite differs from pure Ca brushite in TEM (Figure 2E). Low Mg substitution does not induce localized structural changes: X-ray absorption near edge spectroscopy, ATR-FTIR, and XRD spectra and patterns are all in agreeance with a structure that is unchanged from a pure Ca brushite mineral. The only obvious change upon low Mg incorporation is a decrease in particle size and morphology, which might have an effect upon solubility. Solutions composed of 25:75 to 75:25 (Ca:Mg) produced a modified brushite mineral. The local bonding environment is strongly influenced by the mixed cation solution as the ATR-FTIR spectra and P K-edge XANES of these precipitates is recognizable as a low crystallinity calcium phosphate but are not readily apparent as brushite. Magnesium phosphates do not form in mixed solutions unless the concentration is overwhelmingly in favour of $\mathrm{Mg}(1: 8)$, affirming their lack of study in nature, but not to say they cannot form in localized region with high $\mathrm{Mg}$. As found with the other minerals in this series, the macro-structure via TEM was changed in the mixed solution. The crystal structure and the local bonding environment are newberyite. The observation that Mg-bearing brushite (e.g., at Ca:Mg of 1:1) has a P K-edge XANES spectra that is distinct from pure Ca brushite, and that this identifiable substituted phase occurs at $\mathrm{Ca}: \mathrm{Mg}$ ratios less than those commonly found in nature, including soils, may also be important to the metastability of brushite in soils. The diffraction pattern of Mg-bearing brushite is consistent with that of pure brushite indicating the overall crystal structure is unaffected. However, there are extreme morphological changes presented by TEM images as well as broadening of FTIR bands consistent with many slightly different local bonding environments deriving from strains caused by $\mathrm{Mg}$ incorporation and/or substitution. This is 
in agreement with P K-edge XANES spectra that are similar to the pure brushite mineral but with a lower crystallinity/ordered local environment.

For hydroxyapatite/bobierrite, the addition of $\mathrm{Mg}^{2+}$ generally results in a short-range order (SRO) intermediate phase rather than substantial cation substitution. Overall, SRO hydroxyapatite has ATR-FTIR and P K-edge XANES that are extremely similar to hydroxyapatite, but in SP-XRD and TEM the mineral(s) appear as amorphous and are very small particles. Effectively, this Mg 'influenced' calcium phosphate is an amorphous calcium phosphate where SRO is consistent with hydroxyapatite. It is possible that much of the hydroxyapatite that has been identified within soils with P K-edge XANES is, instead, this short-range order phase rather than pure HAP. It was found that bobierrite is able to form in solutions with a large amount of $\mathrm{Mg}$ without affecting the local bonding environment.

Despite direct observation of brushite and ACP in many calcareous soils using XAS, thermodynamic modeling predicts that hydroxyapatite should be the solubility limiting mineral phase [40]. Consider the following: (1) Ca:P ratio is often much greater than the 1.67:1 ratio that favours the formation of apatite, and (2) soil $\mathrm{pH}$ is often greater than 7 , where minerals such as brushite are unstable due to $\mathrm{HPO}_{4}{ }^{2-}$ dissociation in solution. It is possible that hydroxyapatite is kinetically inhibited, but given the long timeframe of soil formation this seems less than convincing. The findings of this paper lead to alternative explanations for the persistence of poorly crystalline phosphates in the environment that have not been previously considered: (1) Mg inhibition of hydroxyapatite crystallization and propagation, and (2) incorporation of $\mathrm{Mg}$ into the brushite crystal lattice.

\section{Conclusions}

This study produced a library of P K-edge XANES spectra of mixed calcium-magnesium minerals that have not been previously studied or collected. A comprehensive set of spectra from the minerals described in this paper, with two additional synthesis series, monetite $\left(\mathrm{CaHPO}_{4}\right)$ and struvite $\left(\mathrm{NH}_{4} \mathrm{MgPO}_{4} \bullet 6 \mathrm{H}_{2} \mathrm{O}\right)$ can be found in the Supplemental Information (Supplement B). From a mineralogical standpoint, the presence of $\mathrm{Mg}$ in solution has effects on the crystallography and speciation of calcium phosphate minerals. Pure $\mathrm{Mg}$ phases only occurred where there was an overwhelming proportion of $\mathrm{Mg}(\geq 1: 8 \mathrm{Ca}: \mathrm{Mg})$. Phases produced in mixed cationic solutions were observed to be less crystalline and smaller throughout the study, which can be inferred to increase overall mineral solubility. For future spectroscopic studies in acidic or neutral $\mathrm{pH}$ systems containing $\mathrm{Mg}$, it is recommended that a Mg-bearing brushite is considered in P XANES fitting rather than a pure $\mathrm{CaHPO}_{4}$ phase. This phase is likely to be more representative of what is present in soils and an under-fitting of brushite will occur if the Mg-bearing phase is not included. This phase should also be looked for in future studies using microbeam XANES to study local speciation in soils. In basic solutions, Mg quite effectively limits the rapid precipitation of hydroxyapatite, which may be a strong factor in the limited occurrence of HAP in calcareous soils despite being far less soluble than other calcium phosphates. Any inclusion of Mg adversely affects the crystallization of hydroxyapatite but does not alter its spectroscopic signature in XANES or ATR-FTIR. If Mg substitution plays a role in stabilizing brushite and inhibiting HAP formation, this may provide important insight into why crystalline hydroxyapatite is observed in more weathered agricultural soils. In such systems, phosphate and lime (calcium carbonate) are typically applied repeatedly as fertility treatments, but $\mathrm{Mg}$ is depleted due to both plant uptake and leaching. Alternatively, it is possible that where HAP has been identified with P XANES in natural systems that a substantial proportion is, in fact ACP. Future research directions in this field should concern the long term evolution, stability and solubility constants of the minerals formed in Ca:Mg mixed cation solutions.

Supplementary Materials: The following are available online at http:/www.mdpi.com/2571-8789/4/1/8/s1. Supplemental Information A contains 5 figures detailing ATR-FTIR, XANES, and XRD information for mineral samples not included in this manuscript. Supplemental Information B is a spreadsheet of all of the normalized XANES spectra of phosphate minerals produced as part of this research project. 
Author Contributions: D.M.H. synthesized the minerals, collected the XAS, FTIR, XRD, and SEM data, analyzed the results, and drafted the manuscript. J.G.H. provided expertise in XAS and XRD data collection, analysis and interpretation as well as providing editorial comments on the manuscript. D.P. was the Principal Investigator for the project, supervisor for both D.M.H. and J.G.H., and also contributed to experimental design, data analysis, and provided rewrites and revisions of the manuscript. All authors have read and agreed to the published version of the manuscript.

Funding: Funding for this project was provided by the National Science and Engineering Research Council (NSERC) Discovery Grant (Derek Peak) and a NSERC - Federated Co-operatives Limited (FCL) funded College-University Idea2Innovate Grant.

Acknowledgments: The authors thank the CLS beamline staff at SXRMB and CMCF ID-2 for support in data collection. Research described in this paper was performed using the Canadian Light Source, which is supported by the Canada Foundation for Innovation, Natural Sciences and Engineering Research Council of Canada, the University of Saskatchewan, the Government of Saskatchewan, Western Economic Diversification Canada, the National Research Council Canada, and the Canadian Institutes of Health Research. We also acknowledge the support of the University of Saskatchewan Department of Biology Microscopy Lab (Gouosheng Liu) in collection of TEM images.

Conflicts of Interest: The authors declare no conflict of interest.

\section{References}

1. Dorozhkin, S.V. Calcium Orthophosphates: Occurrence, Properties, Biomineralization, Pathological Calcification and Biomimetic Applications. Biomatter 2011, 1, 121-164. [CrossRef] [PubMed]

2. Kar, G.; Hundal, L.S.; Schoenau, J.J.; Peak, D. Direct Chemical Speciation of P in Sequential Chemical Extraction Residues Using P K-Edge X-Ray Absorption near-Edge Structure Spectroscopy. Soil Sci. 2011, 176, 589-595. [CrossRef]

3. Peak, D.; Kar, G.; Hundal, L.; Schoenau, J. Kinetics and Mechanisms of Phosphorus Release in a Soil Amended With Biosolids or Inorganic Fertilizer. Soil Sci. 2012, 177, 183-187. [CrossRef]

4. Manimel Wadu, M.C.W.; Michaelis, V.K.; Kroeker, S.; Akinremi, O.O. Exchangeable Calcium/Magnesium Ratio Affects Phosphorus Behavior in Calcareous Soils. Soil Sci. Soc. Am. J. 2013, 77, 2004. [CrossRef]

5. Johnsson, M.S.; Nancollas, G.H. The Role of Brushite and Octacalcium Phosphate in Apatite Formation. Crit. Rev. Oral Biol. Med. 1992, 3, 61-82. [CrossRef]

6. Valsami-Jones, E. Mineralogical Controls on Phosphorus Recovery from Wastewaters. Mineral. Mag. 2001, 65, 611-620. [CrossRef]

7. Racz, G.; Soper, R. Reaction Products of Orthophosphates in Soils Containing Varying Amounts of Calcium and Magnesium. Can. J. Soil Sci. 1967, 47, 223-230. [CrossRef]

8. Bauge, S.M.Y.; Lavkulich, L.M.; Schreier, H.E. Serpentine Affected Soils and the Formation of Magnesium Phosphates (Struvite). Can. J. Soil Sci. 2013, 93, 161-172. [CrossRef]

9. Vogel, C.; Adam, C.; Sekine, R.; Schiller, T.; Lipie, E.; McNaughton, D. Determination of Phosphorus Fertilizer Soil Reactions by Raman and Synchrotron Infrared Microspectroscopy. Appl. Spectrosc. 2013, 67, 1165-1170. [CrossRef]

10. Siciliano, S.D.; Chen, T.; Phillips, C.; Hamilton, J.; Hilger, D.; Chartrand, B.; Grosskleg, J.; Bradshaw, K.; Carlson, T.; Peak, D. Total Phosphate Influences the Rate of Hydrocarbon Degradation but Phosphate Mineralogy Shapes Microbial Community Composition in Cold-Region Calcareous Soils. Environ. Sci. Technol. 2016, 50, 5197-5206. [CrossRef]

11. Salimi, M.H.; Heughebaert, J.C.; Nancollas, G.H. Crystal Growth of Calcium Phosphates in the Presence of Magnesium Ions. Langmuir 1985, 1, 119-122. [CrossRef]

12. Wang, L.; Nancollas, G.H. Calcium Orthophosphates: Crystallization and Dissolution. Chem. Rev. 2008, 108, 4628-4669. [CrossRef] [PubMed]

13. Cao, X.; Harris, W. Carbonate and Magnesium Interactive Effect on Calcium Phosphate Precipitation. Environ. Sci. Technol. 2008, 42, 436-442. [CrossRef]

14. Boanini, E.; Gazzano, M.; Bigi, A. Ionic Substitutions in Calcium Phosphates Synthesized at Low Temperature. Acta Biomater. 2010, 6, 1882-1894. [CrossRef] 
15. Diallo-Garcia, S.; Laurencin, D.; Krafft, J.M.; Casale, S.; Smith, M.E.; Lauron-Pernot, H.; Costentin, G. Influence of Magnesium Substitution on the Basic Properties of Hydroxyapatites. J. Phys. Chem. C 2011, 115, 24317-24327. [CrossRef]

16. Driessens, F.C.M.; Verbeek, R.M.H. The Calcium Rich Compounds of the System $\mathrm{Ca}(\mathrm{OH}) 2-\mathrm{H} 3 \mathrm{PO} 4-\mathrm{H} 2 \mathrm{O}$; CRC Press: Boca Raton, FL, USA, 1990; pp. 37-59.

17. Cao, X.; Harris, W.G.; Josan, M.S.; Nair, V.D. Inhibition of Calcium Phosphate Precipitation under Environmentally-Relevant Conditions. Sci. Total Environ. 2007, 383, 205-215. [CrossRef]

18. Hesterberg, D. Chapter 11 - Macroscale Chemical Properties and X-Ray Absorption Spectroscopy of Soil Phosphorus. Dev. Soil Sci. 2010, 34, 313-356. [CrossRef]

19. Franke, R.; Hormes, J. The P K-near Edge Absorption Spectra of Phosphates. Phys. B Phys. Condens. Matter 1995, 216, 85-95. [CrossRef]

20. Hesterberg, D.; Zhou, W.; Hutchison, K.J.; Beauchemin, S.; Sayers, D.E. XAFS Study of Adsorbed and Mineral Forms of Phosphate. J. Synchrotron Radiat. 1999, 6, 636-638. [CrossRef]

21. Okude, N.; Nagoshi, M.; Noro, H.; Baba, Y.; Yamamoto, H.; Sasaki, T. P and S K-Edge XANES of Transition-Metal Phosphates and Sulfates. J. Electron Spectros. Relat. Phenomena 1999, 101-103, 607-610. [CrossRef]

22. Werner, F.; Prietzel, J. Standard Protocol and Quality Assessment of Soil Phosphorus Speciation by P K-Edge XANES Spectroscopy. Environ. Sci. Technol. 2015, 49, 10521-10528. [CrossRef] [PubMed]

23. Peak, D.; Sims, J.T.; Sparks, D.L. Solid-State Speciation of Natural and Alum-Amended Poultry Litter Using XANES Spectroscopy. Environ. Sci. Technol. 2002, 36, 4253-4261. [CrossRef] [PubMed]

24. Ajiboye, B.; Akinremi, O.O.; Hu, Y.; Jürgensen, A. XANES Speciation of Phosphorus in Organically Amended and Fertilized Vertisol and Mollisol. Soil Sci. Soc. Am. J. 2008, 72, 1256. [CrossRef]

25. Liu, J.; Yang, J.; Cade-Menun, B.J.; Liang, X.; Hu, Y.; Liu, C.W.; Zhao, Y.; Li, L.; Shi, J. Complementary Phosphorus Speciation in Agricultural Soils by Sequential Fractionation, Solution P Nuclear Magnetic Resonance, and Phosphorus K-Edge X-Ray Absorption Near-Edge Structure Spectroscopy. J. Environ. Qual. 2013, 42, 1763. [CrossRef]

26. Kar, G.; Schoenau, J.; Hilger, D.; Peak, D. Direct Chemical Speciation of Soil Phosphorus in a Saskatchewan Chernozem after Long and Short-Term Manure Amendments. Can. J. Soil Sci. 2017, 11. [CrossRef]

27. Ingall, E.D.; Brandes, J.A.; Diaz, J.M.; De Jonge, M.D.; Paterson, D.; McNulty, I.; Elliott, W.C.; Northrup, P. Phosphorus K-Edge XANES Spectroscopy of Mineral Standards. J. Synchrotron Radiat. 2011, 18, 189-197. [CrossRef]

28. Oxmann, J.F. Technical Note: An X-Ray Absorption Method for the Identification of Calcium Phosphate Species Using Peak-Height Ratios. Biogeosciences 2014, 11, 2169-2183. [CrossRef]

29. Lee, D.; Kumta, P.N. Chemical Synthesis and Characterization of Magnesium Substituted Amorphous Calcium Phosphate (MG-ACP). Mater. Sci. Eng. C 2010, 30, 1313-1317. [CrossRef]

30. Aramendía, M.A.; Borau, V.; Jiménez, C.; Marinas, J.M.; Romero, F.J. Synthesis and Characterization of Magnesium Phosphates and Their Catalytic Properties in the Conversion of 2-Hexanol. J. Colloid Interface Sci. 1999, 217, 288-298.

31. Riman, R.E.; Sever, C. Biomimetic Hydroxyapatite Synthesis. US. Patent 8287914 B2, 16 October 2012.

32. Laurencin, D.; Almora-Barrios, N.; de Leeuw, N.H.; Gervais, C.; Bonhomme, C.; Mauri, F.; Chrzanowski, W.; Knowles, J.C.; Newport, R.J.; Wong, A.; et al. Magnesium Incorporation into Hydroxyapatite. Biomaterials 2011, 32, 1826-1837. [CrossRef]

33. Kolmas, J.; Jaklewicz, A.; Zima, A.; Bućko, M.; Paszkiewicz, Z.; Lis, J.; Ślósarczyk, A.; Kolodziejski, W. Incorporation of Carbonate and Magnesium Ions into Synthetic Hydroxyapatite: The Effect on Physicochemical Properties. J. Mol. Struct. 2011, 987, 40-50. [CrossRef]

34. Toby, B.H.; Von Dreele, R.B. GSAS-II: The Genesis of a Modern Open-Source All Purpose Crystallography Software Package. J. Appl. Crystallogr. 2013, 46, 544-549. [CrossRef]

35. Degen, T.; Sadki, M.; Bron, E.; König, U.; Nénert, G. The HighScore Suite. Powder Diffr. 2014, 29, S13-S18. [CrossRef]

36. Larson, A.C.; Von Dreele, R.B. General Structure Analysis System; report LAUR 86-748; Los Alamos National Laboratory: Los Alamos, NM, USA, 2004. [CrossRef] 
37. Schofield, P.F.; Knight, K.S.; van der Houwen, J.A.M.; Valsami-Jones, E. The Role of Hydrogen Bonding in the Thermal Expansion and Dehydration of Brushite, Di-Calcium Phosphate Dihydrate. Phys. Chem. Miner. 2004, 31, 606-624. [CrossRef]

38. Waseda, Y.; Matsubara, E.; Shinoda, K. X-Ray Diffraction Crystallography; Springer Science \& Business Media: Berlin, Germany, 2011. [CrossRef]

39. Stipniece, L.; Salma-Ancane, K.; Jakovlevs, D.; Borodajenko, N.; Berzina-Cimdina, L. The Study of Magnesium Substitution Effect on Physicochemical Properties of Hydroxyapatite. Mater. Sci. Appl. Chem. 2013, 28, 51. [CrossRef]

40. Lindsay, W.L. Chemical Equilibria in Soils; John Wiley \& Sons: Chichester, UK, 1979.

(C) 2020 by the authors. Licensee MDPI, Basel, Switzerland. This article is an open access article distributed under the terms and conditions of the Creative Commons Attribution (CC BY) license (http://creativecommons.org/licenses/by/4.0/). 